\title{
Volume of Distribution Observed Normalized by Body Mass Index
}

National Cancer Institute

\section{Source}

National Cancer Institute. Volume of Distribution Observed Normalized by Body Mass

Index. NCl Thesaurus. Code C92407.

The observed volume of distribution associated with the terminal slope following intravascular administration divided by the body mass index. 